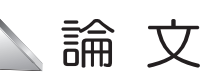

Original Paper

\section{バッチ法に基づく変質火山岩からのヒ素溶出挙動 *}

\title{
Leaching Behavior of Arsenic from Altered Igneous Rocks by Batch Method
}

\author{
by Harue IMAGAWA ${ }^{\mathrm{a}}$, Toshifumi IGARASHI ${ }^{\mathrm{b} *}$, Hiroyuki UCHIYAMA ${ }^{\mathrm{b}}$, \\ Kuniomi ASAKURA ${ }^{b}$
}

a. Division of Environment and Resources Engineering, Graduate School of Engineering, Hokkaido University

b. Division of Field Engineering for Environment, Graduate School of Engineering, Hokkaido University, Kita 13, Nishi 8, Kita-ku, Sapporo-shi, Hokkaido, 060-8628, Japan

(*Corresponding author: E-mail tosifumi@eng.hokudai.ac.jp)

\begin{abstract}
Hydrothermally altered rocks are rich in arsenic (As). Thus the leaching of As from the rocks as muck may affect the surrounding soil and groundwater. The objective of this study is to clarify the leaching behavior of As for eleven crushed rock samples collected in Hokkaido by batch leaching experiments. The results showed that the As concentration in the leachate correlated with the As and sulfur ( $\mathrm{S}$ ) contents in rock and the $\mathrm{SO}_{4}{ }^{2-}$ and $\mathrm{Fe}$ concentrations in leachate, and that pyrite was detected in the rock samples that contained more sulfur. The As was also observed in the pyrite grain of the rock samples by SEM-EDX. This suggests that the mechanism of As release from altered igneous rocks used in the present work is partly explained by the congruent dissolution with pyrite that contains As as impurities. The higher correlation between As concentration in the leachate and As content in the rock means that the As content is used as an effective indicator of the necessity of leaching experiments.
\end{abstract}

KEY WORDS: Arsenic, Altered Igneous Rock, Leaching, Batch Method, Pyrite

\section{1. 緒言}

北海道には火山，温泉，鉱山などが多く，熱水変質した岩盤が 広く分布している。熱水変質を被った岩石にはヒ素 $(\mathrm{As})$ が濃集 されていることが多く1), 含有量, 溶出濃度ともに高い值を示 すことがある。このような地域でトンネル建設などの岩盤掘削を 伴う土木建築工事を行う場合, 発生する掘削ずりに As が含まれ ていることがあり, 降雨などによって As が溶出し周辺の地下水 や土壌などに悪影響を及ぼすことが眯念される。土壌污染対策法 によると，Asに対しては含有量が $150 \mathrm{mg} / \mathrm{kg}$ ，溶出試験における 溶出水中濃度が $0.01 \mathrm{mg} / \mathrm{L}$ を超えるものについては, 人為污染の 場合適切な対策を講ずることが要求されているが, 自然由来の污 染に対する対策までは要求されていない。しかし，トンネルなど の掘削ずりは，元来は自然のものであるが人為的な擾乱が加えら れることから，まったくの自然由来とはいえない。そのため，ず り中の As などの重金属類が土壌污染対策法に定める含有量基準

*2006 年 4 月 5 日受付 2007 年 3 月 3 日受理

1. 学生会員 北海道大学大学院工学研究科環境資源工学専攻 ( 現 日鉱金属 (株))

2. 普通会員 北海道大学大学院工学研究科環境フィールド工学専攻 准教 授

3. 学生会員 北海道大学大学院工学研究科環境フィールド工学専攻 (現 経 済産業省）

4. 普通会員 北海道大学大学院工学研究科環境フィールド工学専攻 教授

[ 著者連絡先 ] TEL / FAX: 011-706-6308

E-mail: tosifumi@eng.hokudai.ac.jp

キーワード : ヒ素, 変質火山岩, 溶出, バッチ法, 黄鉄鉱
や溶出量基準を超える場合, 適切な対策が必要となる。実際, 東 北新幹線八戸以北の八甲田トンネル工事においては，周辺環境一 の悪影響が懸念される鉱化変質岩からなる掘削ずりに対しては シートによる遮水対策を施した管理型処分が行われている ${ }^{2,3)}$ 。

岩盤掘削ずりを含む建設残土に対しては，国土交通省が「建設 工事で遭遇する地盤污染対策マニュアル（暫定版）」を作成して (る ${ }^{4)}$ 。このマニュアルによると，対策は暫定対策と恒久対策 とに大別され, 暫定対策には敷土・覆土, 浮き遮水壁, バリア井 戸，固化・不溶化が挙げられ，恒久対策には環境庁の「土壌・地 下水污染に係わる調查・対策指針および運用基準」5)に準拠する 原位置浄化, 掘削除去, 原位置封じ込め, 掘削除去後封じ込めが 記載されている。人為的な污染であり，かつ污染の程度も深刻な 場合は，上記の恒久対策が必要であると考えられるが，自然由来 の污染で,かつ污染の程度も環境基準を若干上回る程度であれば, もう少し軽微な対策で対応してもよいと考えられる。自然由来の 変質火山岩に対する対策は, まさにこの範疇であり, そのために も, このような変質火山岩からの As のような重金属類の溶出挙 動を明らかにする必要がある。

自然由来の As による地下水污染は全世界的に知られており 1), とくにバングラディシュなどでは深刻である。その原因としては 大きく 2 つの説があり, どちらも酸化還元環境の変化に起因寸る ものである 6-9)。一つ目は, As は Fe と非常に親和性があるため, 黄鉄鉱 (pyrite, $\mathrm{FeS}_{2}$ ) などの硫化物中に As が不純物として共存し たり, 硫砒鉄鉱 (arsenopyrite, FeAsS) の形態となっていたりする 
が，還元状態で安定であるこれらの鉱物が，酸化環境に変化する ことによって溶解するケースである (硫化物酸化説)。二つ目は, 酸化環境で安定している $\mathrm{Fe}$ の酸化物や水酸化物に取り込まれて いる As が，還元環境で Fe とともに再溶出するケースである (酸 化物還元説）。また, どちらのケースか明確でないケースあるい はどちらのケースも起こっているケースもありうる。硫化物酸化 説に該当する事例としては，国内では大阪北摂津地域 ${ }^{10)}$, 国外 では西ベンガル 11,12), ウィンスコンシン東部 13), ニューハンプ シャー ${ }^{14)}$ などがある。酸化物還元説に該当する事例としては,

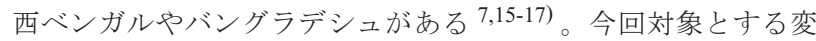
質火山岩からの As 溶出は, これらの事例を参照すると, 硫化物 の酸化に起因することが予想される。

土壌污染対策法では, 直接摂取のリスクと地下水等の摂取によ るリスクの両方に対する対策が要求されているため, As 含有量 が $150 \mathrm{mg} / \mathrm{kg}$ を下回っていても As 溶出濃度が $0.01 \mathrm{mg} / \mathrm{L}$ を超え る場合もあるため, 含有量を測定するだけでは不十分であり, 溶 出試験も行わなければならないというのが実状である。

このような背景から, 本研究ではAs の溶出挙動と岩石の化学 組成, 鉱物組成との関係や, 溶出水水質との関係を把握し, As が溶出する岩石の特徵を明確にするとともに, 管理が必要となる 掘削ずりを効率的に分別する方法について検討する。

\section{2. 試 験 方 法}

\section{$2 \cdot 1$ 岩石試料}

実験に用いた岩石試料は道内のグリーンタフ地域における熱水 変質を被った同一のトンネル掘削地点から採取した 11 種類 (No.1 〜 11) の変質火山岩試料である。なお, No.4，10，11 は試験途 中で試料が不足したため, No.4, 10 に対しては同一切羽の岩石を, No.11 に対しては近傍切羽の岩石を再度採取し, それぞれNo.4', 10'，11'とし追加分析した。なお，後述するように岩石試料の 化学的, 鈗物学的性質は若干の採取位置の相違によっても異なっ た。試料の珪化区分および岩種を Table 1 に示す。表中の珪化の 程度は, 試料の肉眼での観察および周辺の地質調査に基づき定性 的に判断した結果である。岩種としては火砕岩や安山岩で, No.4, 11 が断層部分に対応している。採取した試料は, 風乾後, ジョークラッシャーで $2 \mathrm{~mm}$ 以下に粉砕し, 各試験に供した。

試料中の含有鉱物を明らかにするために, X 線回折 (XRD) 分 析を粉末法に基づき実施した。また, 溶出試験後の試料について も乾燥後, 鉱物組成を分析した。使用した機器はリガク製 MultiFlex である。溶出試験前の結果を Table 2 に示す。この表か ら No.1，2，4，8，11 に黄鉄鉱 $\left(\mathrm{FeS}_{2}\right)$ の存在が確認された。また, 溶出試験後の XRD 分析の結果は, 溶出試験前の結果とほとんど 一致し, 溶出試験後に新たに検出されたピークは見出されなかっ た。なお，今回用いた試料には硫七鉄鉱は検出されなかった。

岩石試料の化学組成を明らかにするために, 蛍光 X 線 (XRF) 法および湿式分析法 ${ }^{18,19)}$ を併用して全岩分析を実施した。使用 した蛍光 X 線分析装置はリガク製のエネルギー分散型 XEPOS お よびシーメンス社製 SRS303AS である。なお，XRF による定量 にあたっては, マトリックス補正を行った検量線法を用いた。岩 石試料に対する $\mathrm{Si}, \mathrm{Ti}, \mathrm{Al}, \mathrm{Fe}, \mathrm{Mn}, \mathrm{Mg}, \mathrm{Ca}, \mathrm{Na}, \mathrm{K}, \mathrm{P}, \mathrm{S}$, As は XRFによって分析した。また, C は小西式無水炭酸定量装 置を用い, 強熱減量 (LOI) は $1000^{\circ} \mathrm{C}$ 乾燥重量法, 結合水 $\left(\mathrm{H}_{2} \mathrm{O}(+)\right)$ はペンフィールド法, 吸着水 $\left(\mathrm{H}_{2} \mathrm{O}(-)\right)$ は $110^{\circ} \mathrm{C}$ 乾燥重量法によっ て分析した。分析結果を Table 3 に示す。この表から As 含有量 は日本の地款表層中の岩石の平均 As 含有量 ${ }^{1)}$ 20) よりも高いもの が多く3〜 $610 \mathrm{mg} / \mathrm{kg}$ に分布した。なお，XRF の定量分析による
Table 1 Rock samples used for leaching experiments.

\begin{tabular}{c|c|c}
\hline Sample & Rock type & Degree of silicification \\
\hline 1 & $\mathrm{~Tb}$ & medium \\
2 & $\mathrm{~Tb}$ & medium \\
3 & $\mathrm{~Tb}$ & medium \\
4 & Gouge in a fault & low \\
4, & $\mathrm{~Tb}$ & low \\
5 & $\mathrm{~Tb}$ & low \\
6 & An & low \\
7 & An & low \\
8 & A-Tb & low \\
9 & A-Tb & low \\
10 & A-Tb & low \\
10 & A-Tb & low \\
11 & Gouge in a fault & low \\
11 ' & Gouge in a fault & low \\
\hline * Tb: Pyroclastic rock, An: Andesite, & \\
A-Tb: Autobrecciated andesite &
\end{tabular}

Table 2 Mineralogical properties of rock samples.

\begin{tabular}{c|l}
\hline Sample & \multicolumn{1}{|c}{ Identified minerals } \\
\hline 1 & Quartz, Orthoclase, Muscovite, Calcite, Kaolinite, Pyrite \\
\hline 2 & Quartz, Orthoclase, Albite, Chlorite, Muscovite, Pyrite \\
\hline 3 & Quartz, Orthoclase, Albite, Muscovite, Kaolinite \\
\hline 4 & Quartz, Orthoclase, Muscovite, Chlorite, Pyrite \\
\hline 4 & Quartz, Orthoclase, Muscovite, Kaolinite, Albite \\
\hline 5 & Quartz, Orthoclase, Calcite, Muscovite, Chlorite \\
\hline 6 & Quartz, Muscovite, Chlorite, Albite, Pyrophyllite \\
\hline 7 & Quartz, Chlorite, Albite \\
\hline 8 & Quartz, Orthoclase, Chlorite, Albite, Pyrite \\
\hline 9 & Quartz, Calcite, Albite, Chlorite \\
\hline 10 & Quartz, Albite, Chlorite \\
\hline $10 '$ & Quartz, Albite, Chlorite \\
\hline 11 & Quartz, Calcite, Muscovite, Chlorite, Pyrite \\
\hline $11 '$ & Quartz, Calcite, Muscovite, Chlorite, Albite \\
\hline
\end{tabular}

As の定量下限は $1 \mathrm{mg} / \mathrm{kg}$ とされているが, Table 3 には表示值と して $0.1 \mathrm{mg} / \mathrm{kg}$ オーダまで示した。また, $\mathrm{FeS}_{2}$ が検出された試料 は As や $\mathrm{S}$ 含有量が多く, $\mathrm{CaO}$ 含有量が比較的少なかった。

局所的な元素含有量分布を把握するために分析走査電子顕微鏡 (SEM-EDX) を用いて切羽岩石の表面観察および面分析を行った。 分析に際しては, 岩石試料の表面を研磨し, カーボンコーティン グし，それに対して島津製作所製分析走査電子顕微鏡 SSX-550 を用いて SEM 観察と EDX 分析を行った。

\section{$2 \cdot 2$ 溶出試験と溶出水分析方法}

$20 \sim 25^{\circ} \mathrm{C}$ の室温条件で，バッチ法に基づき溶出試験を実施し た。試験では, 粉砕試料 $15 \mathrm{~g}$ に脱イオン水 $150 \mathrm{ml}$ を加え, 振と う機を用いて $120 \mathrm{rpm}$ の往復振とうにより 6 時間，1 日，7 日あ るいは 28 日間振とうした。振とう後, 溶液の水温, $\mathrm{pH}$ を測定し, $0.45 \mu \mathrm{m}$ メンブレンフィルターにより固液分離を行い, 万液中の As, $\mathrm{Ca}, \mathrm{Mg}, \mathrm{Na}, \mathrm{K}, \mathrm{Al}, \mathrm{Mn}, \mathrm{Si}, \mathrm{Fe}, \mathrm{HCO}_{3}^{-}$(この場合アル カリ度), $\mathrm{SO}_{4}{ }^{2-}$ の濃度を測定した。なお, $\mathrm{HCO}_{3}{ }^{-}$は硫酸滴定法 により, As は高周波プラズマ質量分析法 (ICP-MS), その他の元 
Table 3 Chemical properties of rock samples.

\begin{tabular}{|c|c|c|c|c|c|c|c|c|c|c|c|c|c|c|c|c|}
\hline Sample & $\begin{array}{c}\mathrm{SiO}_{2} \\
\text { (wt.\%) }\end{array}$ & $\begin{array}{l}\mathrm{TiO}_{2} \\
(\text { wt. \%) }\end{array}$ & $\begin{array}{l}\mathrm{Al}_{2} \mathrm{O}_{3} \\
(\text { wt. \%) }\end{array}$ & $\begin{array}{l}\mathrm{Fe}_{2} \mathrm{O}_{3} \\
(w t . \%)\end{array}$ & $\begin{array}{l}\mathrm{MnO} \\
(\text { wt. \%) }\end{array}$ & $\begin{array}{l}\mathrm{MgO} \\
(w t . \%)\end{array}$ & $\begin{array}{l}\mathrm{CaO} \\
(w t . \%)\end{array}$ & $\begin{array}{l}\mathrm{Na}_{2} \mathrm{O} \\
\text { (wt.\%) }\end{array}$ & $\begin{array}{c}\mathrm{K}_{2} \mathrm{O} \\
(\mathrm{wt} . \%)\end{array}$ & $\begin{array}{l}\mathrm{P}_{2} \mathrm{O}_{5} \\
(\text { wt.\%) }\end{array}$ & $\left\{\begin{array}{c}S \\
(w t . \%)\end{array}\right.$ & $\left\{\begin{array}{c}\text { C } \\
(w t . \%)\end{array}\right.$ & $\begin{array}{c}\text { As } \\
(\mathrm{mg} / \mathrm{kg})\end{array}$ & $\begin{array}{c}\text { LOI } \\
(w t . \%)\end{array}$ & $\left\{\begin{array}{l}\mathrm{H}_{2} \mathrm{O}(+) \\
(w t . \%)\end{array}\right.$ & $\left\{\begin{array}{l}\mathrm{H}_{2} \mathrm{O}(-) \\
(w t . \%)\end{array}\right.$ \\
\hline 1 & 64.2 & 0.42 & 13.6 & 4.53 & 0.38 & 1.31 & 2.42 & 0.16 & 8.48 & 0.08 & 0.45 & 0.59 & 107 & 2.63 & 2.05 & 0.40 \\
\hline 2 & 55.2 & 1.12 & 18.2 & 7.84 & 0.45 & 2.42 & 0.80 & 1.17 & 8.75 & 0.18 & 0.53 & 0.17 & 265 & 3.68 & 2.97 & 0.74 \\
\hline 3 & 64.0 & 0.62 & 16.2 & 4.58 & 0.22 & 2.13 & 1.41 & 1.30 & 5.87 & 0.11 & 0.03 & 0.33 & 27.0 & 3.16 & 3.09 & 1.75 \\
\hline 4 & 67.4 & 0.58 & 14.3 & 4.70 & 0.08 & 1.81 & 0.27 & 0.06 & 6.30 & 0.12 & 0.55 & 0.11 & 116 & 3.94 & 2.35 & 0.72 \\
\hline $4^{\prime}$ & 71.7 & 0.34 & 15.2 & 2.72 & 0.06 & 2.98 & 0.95 & 0.24 & 4.49 & 0.05 & 0.16 & - & 52.2 & - & - & - \\
\hline 5 & 65.9 & 0.37 & 13.5 & 4.06 & 0.14 & 3.16 & 2.03 & 0.47 & 5.57 & 0.08 & 0.25 & 0.47 & 15.0 & 3.41 & 2.97 & 1.04 \\
\hline 6 & 49.0 & 0.92 & 17.7 & 8.37 & 0.15 & 7.23 & 5.12 & 2.79 & 1.78 & 0.22 & 0.11 & 0.72 & 5.0 & 6.05 & 5.80 & 1.63 \\
\hline 7 & 55.8 & 0.88 & 17.1 & 7.07 & 0.13 & 5.18 & 8.04 & 2.61 & 1.32 & 0.22 & $<0.01$ & 0.12 & 5.0 & 1.55 & 1.50 & 0.83 \\
\hline 8 & 54.3 & 0.92 & 17.6 & 7.45 & 0.14 & 6.15 & 1.87 & 4.96 & 2.15 & 0.21 & 0.32 & 0.13 & 611 & 3.84 & 3.60 & 0.95 \\
\hline 9 & 54.1 & 0.86 & 16.5 & 7.60 & 0.11 & 5.67 & 5.29 & 3.50 & 1.55 & 0.20 & $<0.01$ & 0.51 & 4.0 & 4.11 & 4.00 & 1.75 \\
\hline 10 & 55.7 & 0.90 & 17.3 & 7.16 & 0.08 & 4.51 & 7.66 & 2.83 & 0.66 & 0.22 & 0.03 & 0.38 & 7.0 & 2.72 & 2.59 & 0.77 \\
\hline $10^{\prime}$ & 53.4 & 0.98 & 14.4 & 7.70 & 0.10 & 7.93 & 6.41 & 1.93 & 1.29 & 0.19 & 0.12 & - & 2.5 & - & - & - \\
\hline 11 & 38.4 & 1.20 & 22.8 & 11.4 & 0.11 & 5.80 & 3.91 & 0.10 & 4.91 & 0.28 & 0.76 & 0.78 & 40.0 & 9.34 & 4.85 & 9.84 \\
\hline $11^{\prime}$ & 49.9 & 1.19 & 19.2 & 6.96 & 0.14 & 9.41 & 6.65 & 0.22 & 3.55 & 0.22 & 0.33 & - & 14.3 & - & - & - \\
\hline
\end{tabular}

素はプラズマ発光分析法 (ICP-AES) により分析した。 $\mathrm{SO}_{4}{ }^{2-}$ に関 しては, イオンクロマトグラフ法による $\mathrm{SO}_{4}^{2-}-\mathrm{S}$ 分析結果と ICPAES による全 S の分析結果とが一致したため, ICP-AES を用い て全 $\mathrm{S}$ を分析し，それを $\mathrm{SO}_{4}{ }^{2-}$ に換算した。 $\mathrm{Na}, \mathrm{K}$ に関しては, 溶出水中濃度が $0.5 \mathrm{mg} / \mathrm{L}$ 以上であったため ICP-AES で定量した。 ICP-AES は島津製作所製ICPS-7500 を使用し，ICP-MS は島津製 作所製ICPM-8500 を使用した。

\section{3. 結果と考察}

\section{$3 \cdot 1$ 溶出水中の元素濃度変化}

粉砕岩石試料からの溶出水の水質変化を測定した。溶出水 $\mathrm{pH}$ の変化を Fig. 1 に, 溶出水中の $\mathrm{As}, \mathrm{Ca}, \mathrm{SO}_{4}{ }^{2-}, \mathrm{Si}, \mathrm{Fe}$ の濃度変 化を Fig. $2 \sim 6$ に, 溶出水のアルカリ度変化を Fig. 7 にそれぞ れ示す。Fig. 1 から, pH は No.4 を除き溶出時間 6 時間あるいは 1 日では $\mathrm{pH} 8.2 \sim 9.7$ に分布するが，溶出時間 7 日以降は $\mathrm{pH} 8.2$ 〜 8.4 に収束した。No.4 は溶出時間にかかわらず $\mathrm{pH} 4$ 弱の酸性 を呈した。Asについては, Fig. 2 から溶出時間の増加とともに As 濃度が徐々に増加することがわかる。しかし，7 日後の濃度 と 28 日後の濃度とがどの試料に対してもほぼ等しいことから，7 日間振とうによってほぼ平衡濃度に達したと判断される。このこ

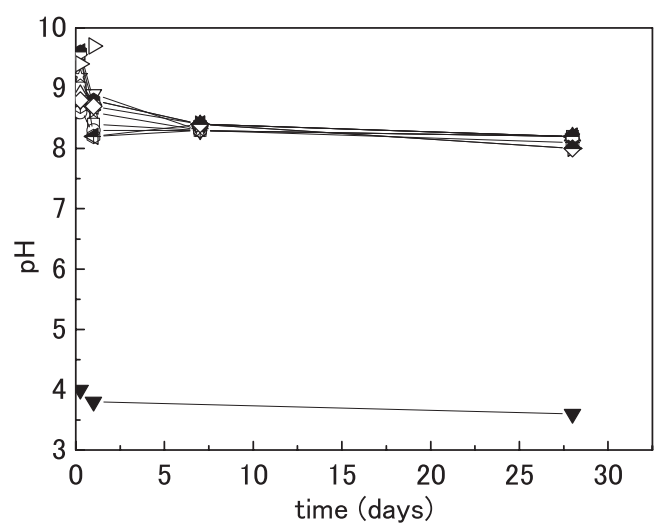

Fig.1 $\mathrm{pH}$ change in leachate.
とは, Fig. 1 に示した pH 変化とも対応し, 溶出水 $\mathrm{pH}$ が安定する と, 溶出水中の As 濃度も一定になることを示唆する。Fig. 2 か ら As の溶出基準である $10 \mu \mathrm{g} / \mathrm{L}$ を超える試料は No.2，4，4， 8 , 11'であった。その他の試料は 28 日の振とう時間を確保しても 基準值を超えることはなかった。

その他の元素に関しては, 一例として Fig. 3 ～6 に示すように,

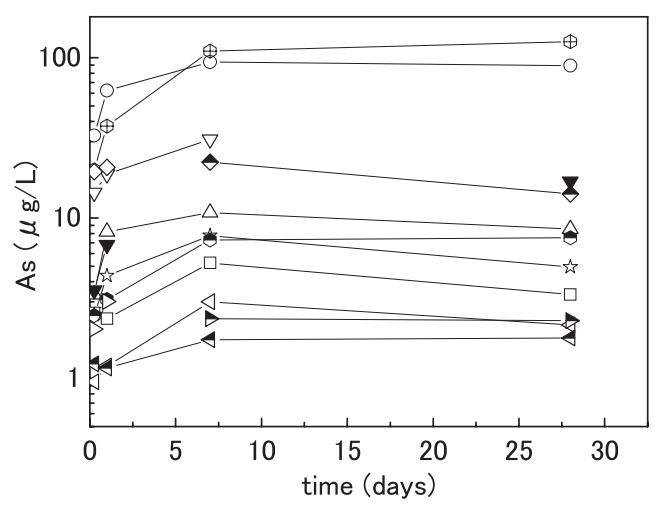

Fig.2 As concentration change in leachate.

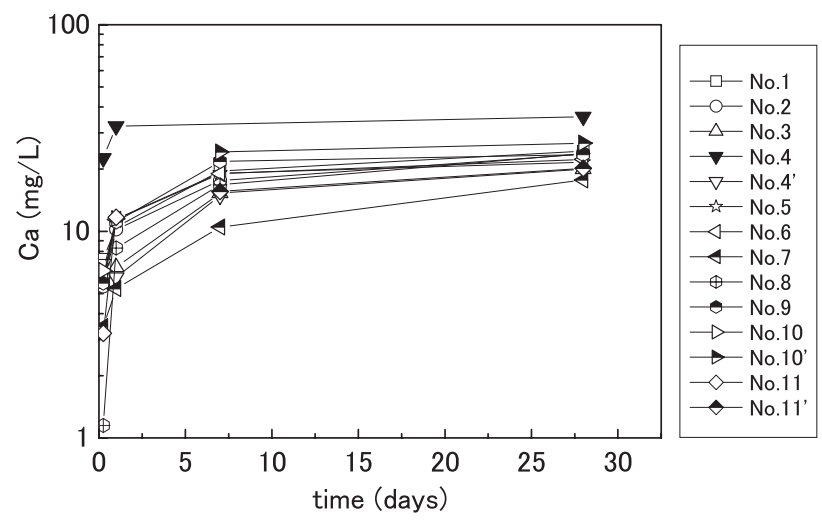

Fig.3 Ca concentration change in leachate. 


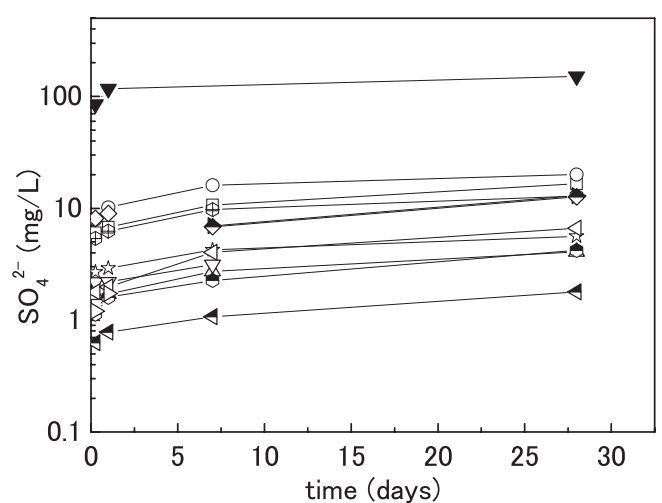

Fig.4 $\mathrm{SO}_{4}{ }^{2-}$ concentration change in leachate.

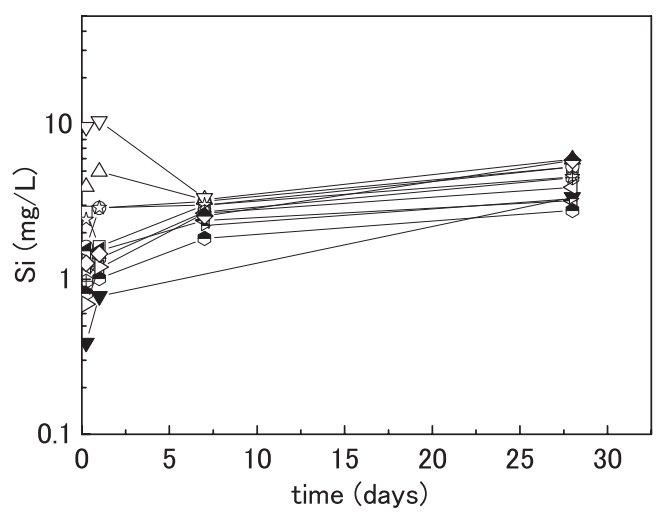

Fig.5 Si concentration change in leachate.

溶出時間の増加とともに, 除々に濃度が増加し一定値を示す元素 $\left(\mathrm{Ca}, \mathrm{Mg}, \mathrm{Na}, \mathrm{K}, \mathrm{SO}_{4}{ }^{2-}, \mathrm{Mn}\right)$ や, 溶出初期の濃度は高いが $\mathrm{pH}$ の収束によって濃度が安定する元素 $(\mathrm{Si}, \mathrm{Fe}, \mathrm{Al})$ などがあること がわかった。後者の挙動を示す元素は, アルカリ性で溶解しやす い性質を有寸るため, 溶出初期の高 $\mathrm{pH}$ 時に溶出濃度がいったん 高くなり, 溶出時間の増加により $\mathrm{pH}$ が低下寸ると, それらの濃 度も減少することになる。 Feについては, $\mathrm{Si}$ や $\mathrm{Al}$ とは異なり, 岩石中では Fe (II) の形態であり Fe (II) として溶出するが，大気 環境下での溶出のため Fe (III) に酸化する。そのため中性付近で は $\mathrm{Fe}(\mathrm{OH})_{3}$ となり再沈殿するが，アルカリ性では $\mathrm{Fe}(\mathrm{OH})_{4}$ - と なり沈殿しない。このような $\mathrm{pH}$ 変化が， $\mathrm{Si}, \mathrm{Fe}, \mathrm{Al}$ の濃度変動 に影響すると考えられる。 $\mathrm{As}$ の溶出濃度変化は, $\mathrm{Ca}$ や $\mathrm{SO}_{4}{ }^{2-}$ の ように溶出時間とともに徐々に溶出濃度が増加する傾向と一致し ている。

アルカリ度に関しては Fig. 7 に示すように, 酸性試料の No.4 はゼロであるが，No.1，2，3，5 で溶出時間の増加とともに上昇 するが，No.7， 8，10，11 で溶出時間の増加による顕著な上昇は 見られない。これらの溶出挙動の差異は, 炭酸塩などの溶解によ るアルカリ度の生成と黄鉄鉱の酸化・溶解による硫酸の生成の両 方によると考えられるが 18,19)，アルカリ度としては $0.3 \sim 4$ $\mathrm{meq} / \mathrm{L}$ に分布する。

No.4 は, Fig. 1 からわかるように唯一酸性を呈する試料である。 Fig. 3，4，6から，他の試料に比べ Fe, $\mathrm{SO}_{4}{ }^{2-}, \mathrm{Ca}$ の濃度が 1 オー ダー近く高くなっていることがわかる。これは Table 2, 3 より No.4 は $\mathrm{FeS}_{2}$ が検出され, $\mathrm{CaO}$ 含有量にそしく $\mathrm{S}$ 含有量が比較的 多いため, $\mathrm{FeS}_{2}$ の酸化により溶出水が硫酸酸性化し, $\mathrm{Fe}, \mathrm{SO}_{4}{ }^{2-}$ の濃度が高くなったと考えられる ${ }^{2,18)}$ 。

\section{$3 \cdot 2$ 溶出水中 As 濃度と他元素濃度との関係}
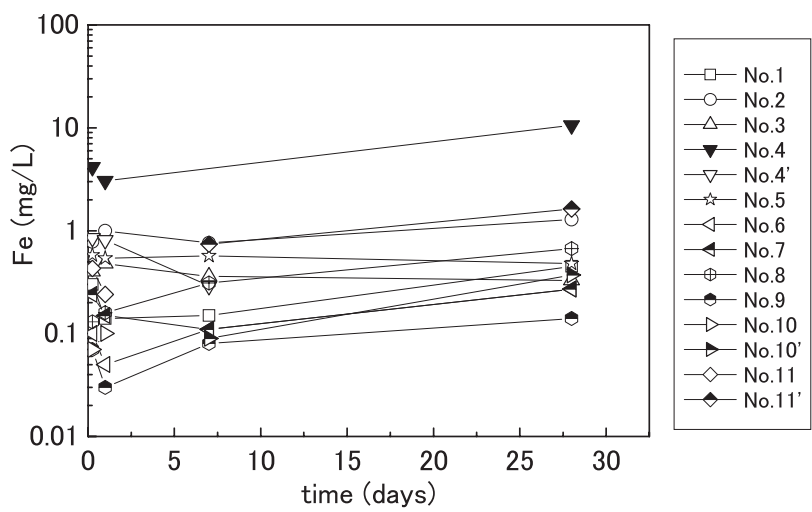

Fig.6 Fe concentration change in leachate.
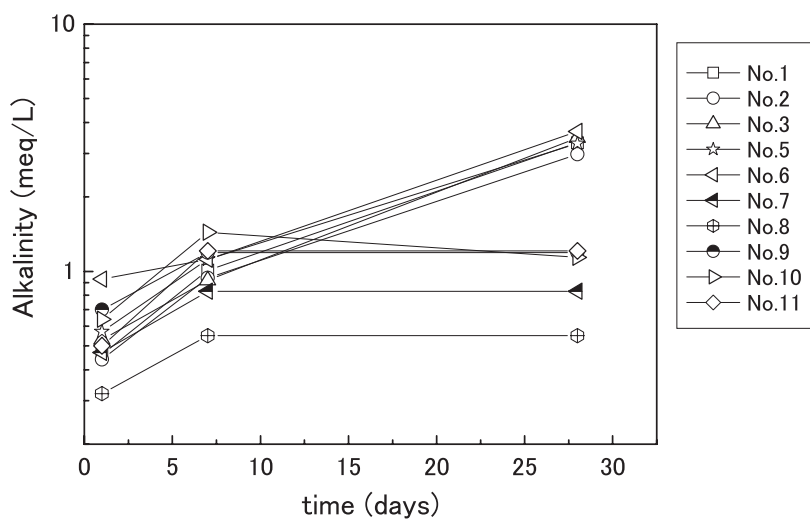

Fig.7 Alkalinity change in leachate

As の溶出挙動は溶出水の化学組成の影響を受けることが予想 されることから, 溶出水中 As 濃度と他元素濃度との関係を調べ た。Fig. 8 は As 濃度と $\mathrm{SO}_{4}{ }^{2-}$ 濃度との関係を, Fig. 9 は As 濃度 と $\mathrm{Fe}$ 濃度との関係を示す。どちらの図も凡例は試料名ではなく 溶出時間とした。なお, No.4のみデータを円で囲んでいる。図 中の直線は, 溶出水の As 濃度が安定する溶出時間 7 日のデータ に対する最小 2 乗法によって得られた直線である。これらの図か ら $\mathrm{SO}_{4}{ }^{2-}$ 濃度や $\mathrm{Fe}$ 濃度の増加とともに $\mathrm{As}$ 溶出濃度も増加するこ とがわかる。このことは岩石中の $\mathrm{FeS}_{2}$ の酸化・溶解にともなっ て As が溶出することを示唆する。ただし, No.4 は溶出水が酸性 となったために, Fig. 4，6からもわかるように他の試料に比べ $\mathrm{SO}_{4}{ }^{2-}$ 濃度と $\mathrm{Fe}$ 濃度が 1 オーダ程度以上高くなった。しかし, As 濃度はそれほど高くはならなかった。後述するように, As 含 有量と $\mathrm{S}$ 含有量とは対応することから, No.4 に対しては, 黄鉄 鉱中の As の存在形態が他試料と異なっていることが原因の一つ と考えられる。すなわち, No.4 は断層粘土試料であり, さらに 酸性を呈していることで溶出しやすいAs はすでに溶出し, 溶出 しにくいAs が残存していると考えられる。

その他の元素に関しては，As 溶出濃度との明瞭な相関関係は 見られなかった。

\section{$3 \cdot 3$ 溶出水中 As 濃度と各元素含有量との関係}

As の溶出挙動は岩石の化学組成や鉱物組成に影響されること から, 溶出水中 As 濃度と岩石試料中の各元素含有量との関係を 調べた。Fig. 10 はAs 溶出濃度とAs 含有量との関係, Fig. 11 は As 溶出濃度と $\mathrm{S}$ 含有量との関係を示す。どちらの図も Fig. 8, 9 に示したように凡例を溶出時間とし, 溶出時間 7 日の結果に対寸 る最小 2 乗法によって得られた直線関係を示寸。これらの図から, $\mathrm{As}$ 溶出濃度は As 含有量, S 含有量との間に正の相関が認められ 


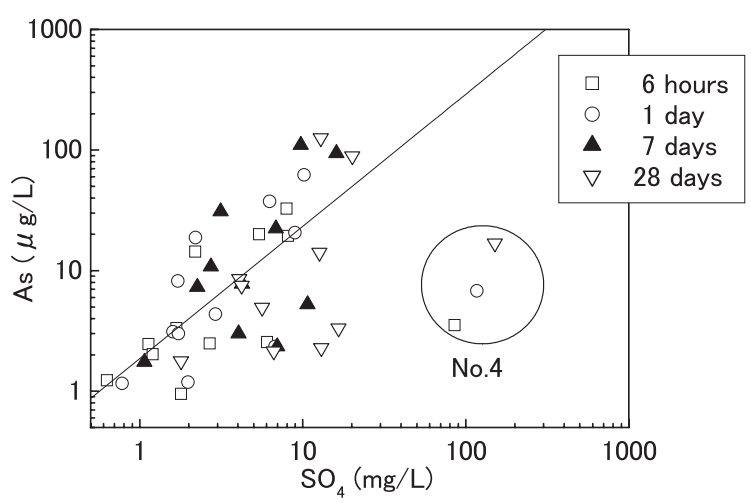

Fig.8 Relation between As concentration and $\mathrm{SO}_{4}{ }^{2-}$ concentration in leachate.

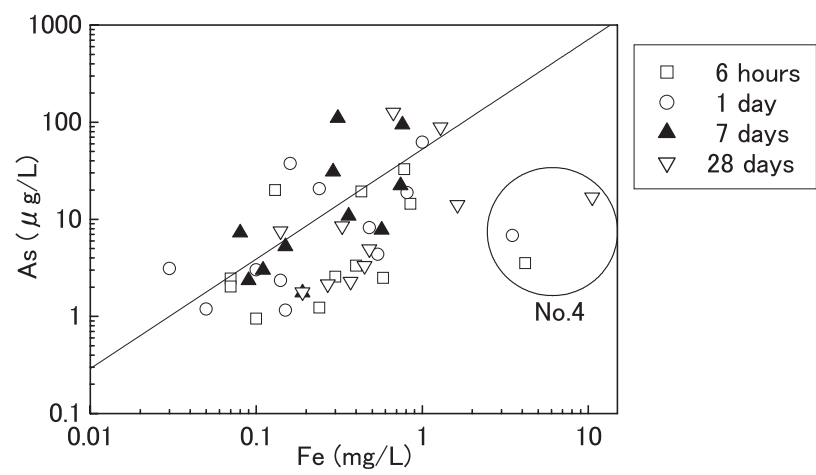

Fig.9 Relation between As concentration and Fe concentration in leachate.

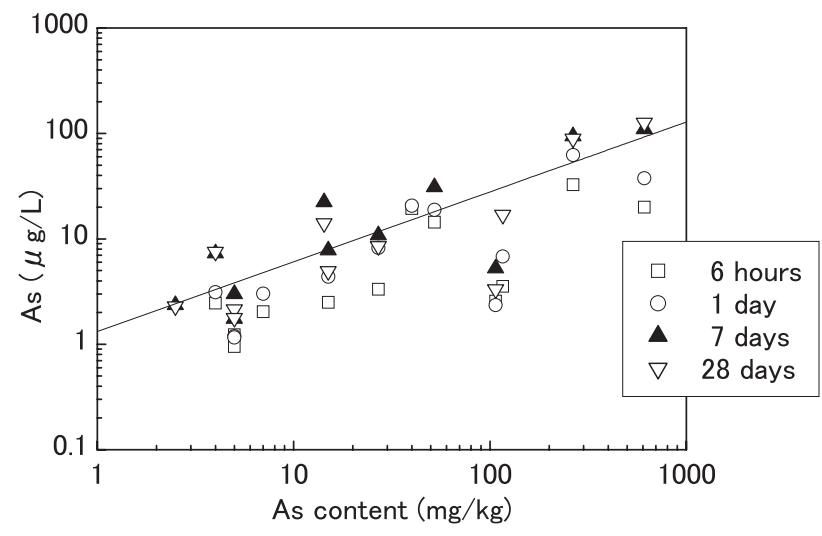

Fig.10 Relation between As concentration in leachate and As content of rock samples.

る。一方，As 溶出濃度と $\mathrm{CaO}$ 含有量との関係を Fig. 12 に示す。 この図から, No.4 を除くと, $\mathrm{CaO}$ 含有量が増加すると As 溶出濃 度が低くなる傾向が見られる。As 溶出濃度と Fe 含有量との関係 をFig. 13 に示す。As 溶出濃度は, Fig. 9 に示したように溶出水 中の $\mathrm{Fe}$ 濃度との相関があったため, $\mathrm{Fe}$ 含有量との関係も確認し た。Fig. 13 からわかるように Fe 含有量と As 溶出濃度との間に は相関関係は認められなかった。これは, 岩石中の $\mathrm{Fe}$ の中で $\mathrm{FeS}_{2}$ の形態は微量であることを示寸。一方, $\mathrm{FeS}_{2}$ の $\mathrm{S}$ につては, Fig. 11 に示したように As 溶出濃度との相関が若干認められたこ とから, 岩石中の $\mathrm{S}$ の大部分が $\mathrm{FeS}_{2}$ の形態であると推定される。 その他の元素含有量と As 溶出濃度との相関は認められなかった。

これらの結果より，As 溶出に関しては As 含有量や S 含有量が 増加すると溶出濃度は上昇寸ること, $\mathrm{FeS}_{2}$ のもう一方の元素で

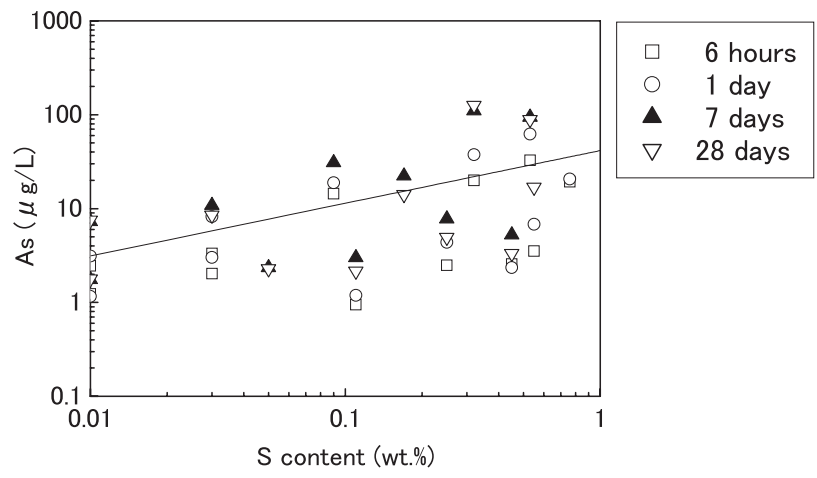

Fig.11 Relation between As concentration in leachate and $\mathrm{S}$ content of rock samples.

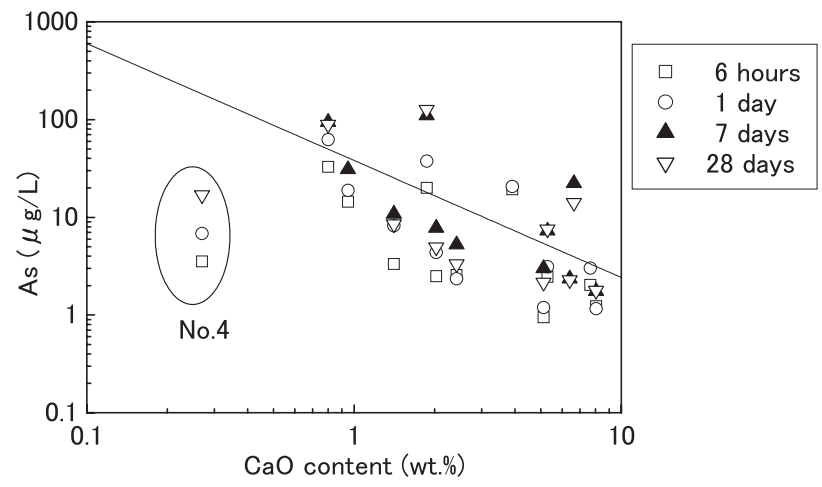

Fig.12 Relation between As concentration in leachate and $\mathrm{CaO}$ content of rock samples.

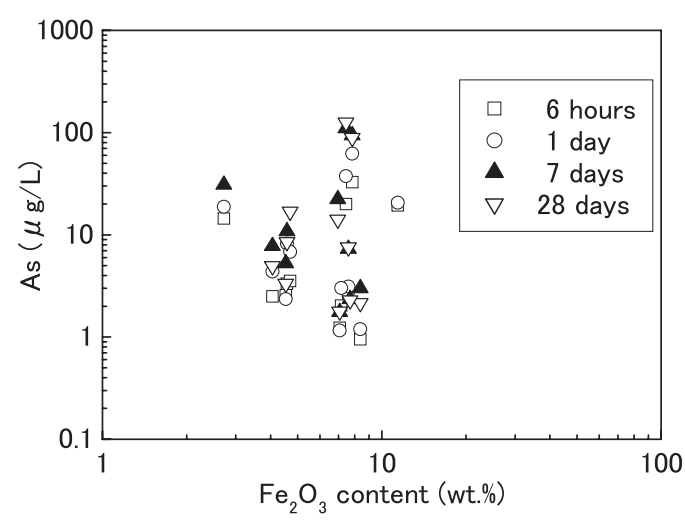

Fig.13 Relation between As concentration in leachate and $\mathrm{Fe}_{2} \mathrm{O}_{3}$ content of rock samples.

ある $\mathrm{Fe}$ には $\mathrm{FeS}_{2}$ 以外の形態も存在するため $\mathrm{Fe}$ 含有量の影響は 明瞭ではないことがわかった。

土壌污染対策法に基づく溶出試験で採用されている 6 時間振と うだけに着目すると, Fig. 10 から As 含有量が約 $30 \mathrm{mg} / \mathrm{kg}$ 以上に なると As 溶出濃度が $10 \mu \mathrm{g} / \mathrm{L}$ を超えると読み取ることができる。 このことは，今回対象とした変質火山岩に対しては，As 含有量 基準である $150 \mathrm{mg} / \mathrm{kg}$ を満足しても，As 溶出量基準 $10 \mu \mathrm{g} / \mathrm{L}$ を満 足しない試料が存在することを示す。

\section{3・ 4 As 含有量と他元素含有量との関係}

岩石中のAs 含有量と他元素含有量との関係についても調べた。 Fig. 14 はAs 含有量と S 含有量との関係を示す。この図から, As 含有量と $\mathrm{S}$ 含有量との間には正の相関が認められる。As 含有 量と $\mathrm{K}$ 含有量との関係においても弱い正の相関が認められた。 


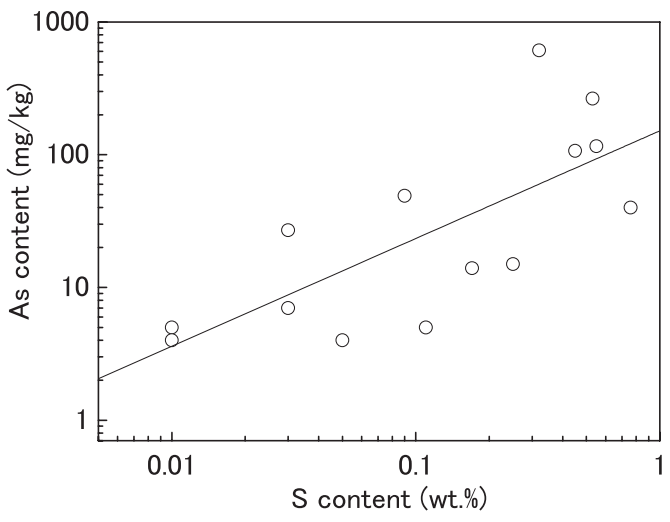

Fig.14 Relation between As content and S content of rock samples.

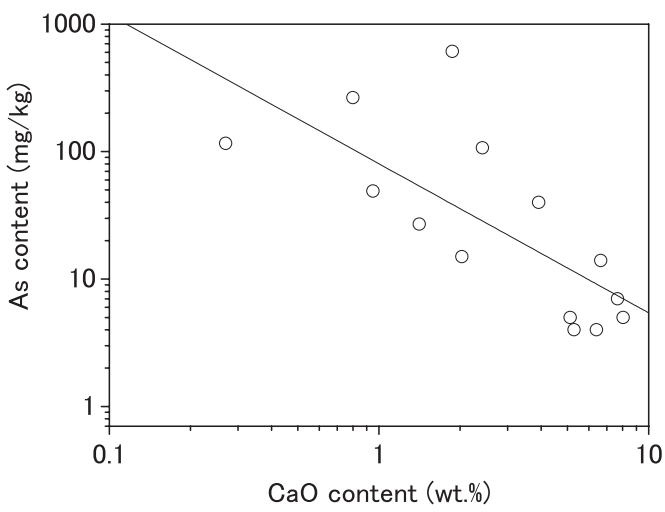

Fig.15 Relation between As content and $\mathrm{CaO}$ content of rock samples.

一方, Fig. 15 に示すように As 含有量と Ca 含有量との間には負 の相関が認められる。その他の元素含有量とAs 含有量との間に は明瞭な関係は見られなかった。これらの結果から, 岩石からの As 溶出濃度が高い試料は, As 含有量のほか $\mathrm{S}$ 含有量も高く, $\mathrm{FeS}_{2}$ の酸化・溶解にともない As が溶出することが明らかになった。

岩石中の As は熱水変質作用あるいは珪化作用に起因する。し たがって, 珪化作用の一つの指標である $\mathrm{FeS}_{2}$ すなわち $\mathrm{S}$ 含有量 はAs 含有量と対応するといえる。また, 珪化作用によって岩石 中の $\mathrm{Ca}$ などの含有量も減少することから, Ca 含有量と As 含有 量とが負の相関を有することになる。Fig. 14，15 は珪化作用に よるAs 含有を示している。

\section{$3 \cdot 5$ 岩石表面の観察と面分析}

溶出試験からは $\mathrm{FeS}_{2}$ と As との溶解反応が調和して発現するこ とが認められたが，岩石中でそれらの含有量分布が一致するかど うかを確認するために, 岩石表面のデータとして SEM-EDXを用 いて近傍切羽の岩石の表面観察および面分析を行った。薄片試料 の SEM 画像を Fig. 16 (a) に示す。図中の中央部に位置する粒子 は Fig. 16 (b)，(c) の同一画面における EDX マッピング結果から $\mathrm{FeS}_{2}$ であると判断される。Fig. 16 (d) の As 含有量分布は Fe や S の含有量分布とも一致することから， $\mathrm{FeS}_{2}$ 中に $\mathrm{As}$ が含まれるこ とを示す。Fig. 16 (e) は Caの EDX マッピング結果を示す。この 図から, $\mathrm{Ca}$ は $\mathrm{FeS}_{2}$ 以外の部分に存在寸ることがわかる。このこ とは, Fig. 12 の As 溶出濃度と Ca 含有量の負の相関関係や Fig 15 の As 含有量と $\mathrm{Ca}$ 含有量の負の相関関係を裏付ける結果であ る。なお, Fig. 16 (b) 〜 (e) の色分けは特性 X 線のカウント数で, 含有量とおおむね対応寸る。

以上のことから，本試験で用いた変質火山岩試料に対する As 溶出は, 試料中の $\mathrm{FeS}_{2}$ に含まれる $\mathrm{As}_{\text {が }} \mathrm{FeS}_{2}$ の酸化にともなっ
て溶出することが明らかになった。さらに, As 溶出濃度は As 含 有量あるいは $\mathrm{FeS}_{2}$ 含有量の増加とともに上昇し, As 含有量が 30 $\mathrm{mg} / \mathrm{kg}$ 以上で溶出量基準 $10 \mu \mathrm{g} / \mathrm{L}$ を上回ることがわかった。

\section{4. 土袞污染対策法からみた岩盤掘削ずりに対する対策の考え方}

土壌污染対策法では，重金属類に対しては含有量と溶出量の基 準が設けられている。この法律における含有量は全岩分析による 含有量ではなく, $1 \mathrm{~N}$ 塩酸によって抽出される量のことであり, 全岩分析による含有量よりは低い值となる。本研究の対象とした 変質火山岩からの As 溶出に関しては，全岩分析による含有量は 基準值以下でも溶出量が基準值を上回る試料が存在したが，溶出 量が基準值以下で含有量が基準值を上回る試料は存在しなかっ た。このことは, 溶出量, 寸なわち溶出濃度が基準值以下であれ ば全岩分析による含有量, ましてや $1 \mathrm{~N}$ 塩酸抽出量も基準值以下 となることを示唆する。したがって, 発生する岩盤掘削ずりが土 壌污染対策法に基づく污染ずりか非污染ずりかを区分する場合, As に対しては溶出濃度だけを測定すればよいということになる。 すなわち, 変質火山岩に対する本研究結果を踏まえると, As に 対しては溶出試験のみによってずりに対する対策の必要性の有無 を判断できるといえる。

溶出試験では，公定法では粉砕試料と脱イオン水との 6 時間に 及ぶ攪拌を行い, その後のろ過とろ液の分析が必要となる。変質 帯の多い北海道のような地域でのトンネル工事においては，でき るだけ早期に対策が必要なずりかそうでないずりかを分別する必 要がある。このため, 溶出試験よりも迅速に判断できる方法が望 ましい。今回採用した XRF 分析による As 含有量と溶出試験に よる As 溶出量とにバラツキが存在するものの相関関係が認めら れた。したがって, XRFによって溶出試験の必要性を判断する ことはできると考えられる。この際, As 含有量が低くても As 溶 出量が高い場合もあるので, 計画・調查段階であらかじめ As 溶 出量とAs 含有量との関係を把握し, 溶出試験を実施すべき岩石 試料の As 含有量を安全側の低い值に設定しておく必要がある。 このことによって溶出試験の検体数の低減, ひいてはずり分別の 迅速化を図ることができると考えられる。一方, As 溶出量と S 含有量との間には相関関係は認められるが, そのバラツキが大き いため, $\mathrm{S}$ 含有量から溶出試験の実施の可否を判断することは難 しいと考えられる。

また，今回用いた No.4 試料のように溶出水が酸性を呈する場 合, これを他の試料と混合して処分すると本来の弱アルカリ性で はAs を溶出しない試料でも, 酸性環境下で溶出しやすくなるこ とも予想される。したがって, 溶出水が酸性を呈するずりに対し ても遮水などの対策を講じ, 他のずりへの影響を除去する必要が ある。

\section{5. 結言}

本研究では, 熱水変質を被った火山岩類を対象として As の溶 出試験を行った。その結果，以下のことが明らかになった。

(1) $\mathrm{As}$ 溶出濃度は $\mathrm{As}$ 含有量, $\mathrm{S}$ 含有量, $\mathrm{SO}_{4}{ }^{2-}$ 溶出濃度, $\mathrm{Fe}$ 溶出濃度と正の相関関係があった。また, $\mathrm{S}$ を含有する試 料には黄鉄鉱 $\left(\mathrm{FeS}_{2}\right)$ が検出されたことから, 岩石中の $\mathrm{S}$ は 主に $\mathrm{FeS}_{2}$ であり, As 溶出には $\mathrm{FeS}_{2}$ が関与することが推定 された。

(2) SEM-EDX による岩石表面の観察および面分析の結果によ ると, $\mathrm{S}$ と $\mathrm{Fe}$ の多い部分に As が多く存在することが認め られた。

(3)これらのことから, As は $\mathrm{FeS}_{2}$ の酸化・溶解反応にともなっ 


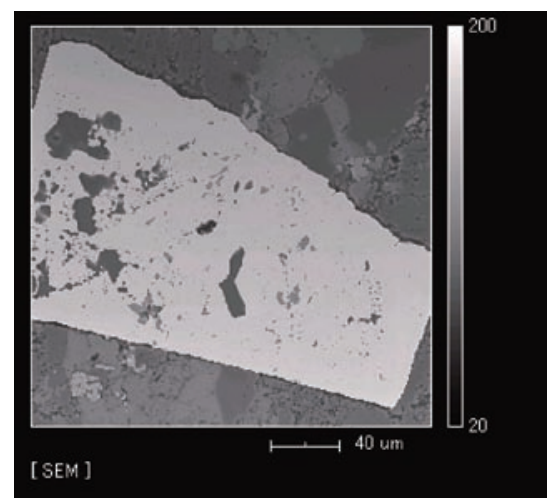

(a) SEM image of the altered igneous rock surface

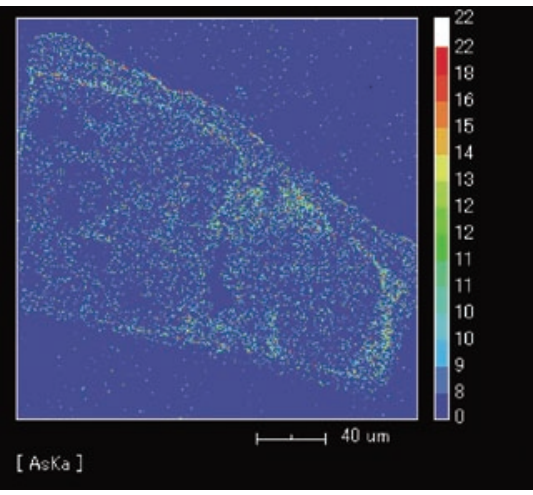

(d) As distribution by SEM-EDX

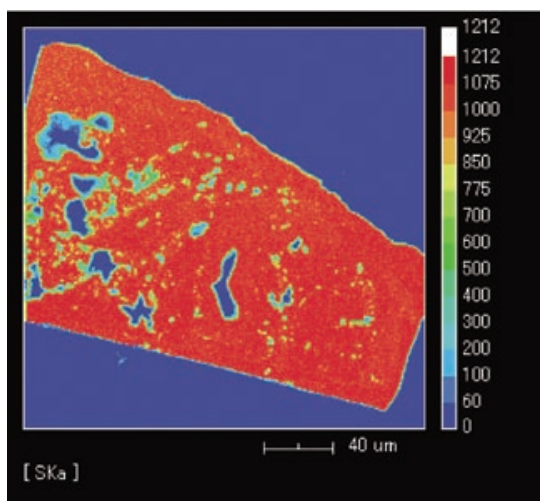

(b) S distribution by SEM-EDX

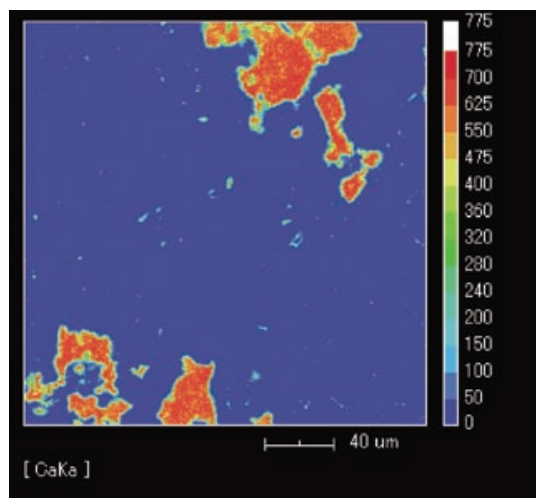

(e) Ca distribution by SEM-EDX

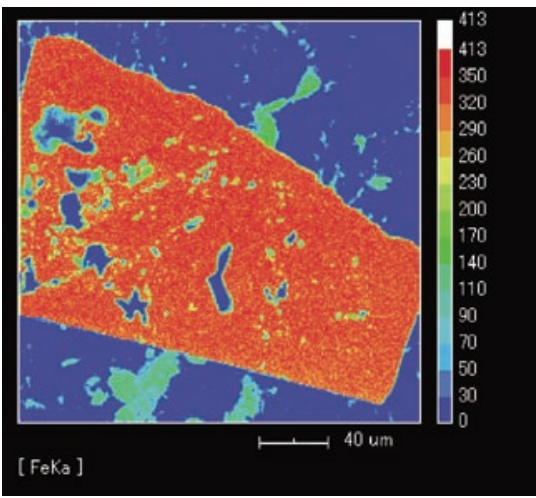

(c) Fe distribution by SEM-EDX

Fig.16 The results of SEM-EDX observations.

て溶出すると判断される。

(4) 埋め立てに対して対策を必要とする岩石を分別する場合, As 含有量と As 溶出濃度との相関性が比較的高かったこと から，As 含有量から As 溶出濃度をおおむね推定できると 考えられる。しかし, As 分布の不均一性を考慮すると, 溶 出試験の必要性のある試料を As 含有量に基づき選別するこ とが妥当であるといえる。

今後の課題として, 変質火山岩以外の岩石試料の As 溶出挙動 や各岩種を混合した場合の As 溶出挙動を明らかにするとともに, 溶出環境による As 溶出挙動の相違を明らかにする必要がある。 これらの成果を踏まえ，重金属類の含有する岩盤掘削ずりの埋立 処分の合理化を図っていきたい。

謝辞本研究で実施したはXRD，XRF，ICP-MSの分析に関 しては幌延地圈環境研究所の若浜洋氏 (現 (株) ダイヤコンサルタ ント), 平井祐次郎氏 (現 北海道電力 (株)) をはじめとする研究 員のご協力を頂いた。また，分析走査電子顕微鏡の使用に際して は, (株) 島津総合分析試験センターのご協力を頂いた。ここに感 謝申し上げる。

\section{References}

1) Y.Kubota: The Special Issue of "Chigaku Kyoiku to Kagaku Undo" , The Association fo the Geological Collaboration in Japan(1997), pp.53-56.
2) S.Hattori, T.Ohta, and H.Kiya: Jour.Japan Soc.Eng.Geol., 43(2003), 359-371.

3) M.Sasaki, H.Kimura, M.Akazawa and T.Hasegawa: Soil Mechanics and Foundation Engineering, 53-5(2005), 8-10

4) Public Works Research Institute: Kensetsu koji de sogu suru jiban osen taio manual, (Kajima Institute Publishing Co.,Ltd., 2004).

5) Ministry of the Environment: Dojyo chikasui osen ni kakawaru chosa taisaku shisin unyo kijun, (Printing Bureau of Ministry of Finance Japan, 1999)

6) N.Shimada: Applied Organometallic Chemistry, 10(1996), 667-674.

7) P.L.Smedley and D.G.Kinniburgh: Applied Geochemistry, 17(2002), 517-568.

8) T.Yoshimura and J.Akai: Earth Sience, 57(2003), 137-154.

9) J.Akai, K.Izumi, H.Fukuhara, H.Masuda, S.Nakano, T.Yoshimura, H.Ohfuji, H.M.Anawar, and K.Akai: Applied Geochemistry, 19(2004), 215-230.

10) H.Masuda, Y.Ibuki, and K.Tonokai: Journal of Groundwater Hydrology, 14(1999), 133-146.

11) B.K.Mandal, T.G.Chowdhury, G.Samanta, D.Mukherjee, C.R.Chanda, K.Saha and D.Chakraborti: Sci.Total Environ., 218(1998), 185-201.

12) D.Chakraborti, G.K.Basu, B.K.Biswas, U.K.Chowdhury, M.M.Rahman, K.Paul, T.R.Chowdhury, C.R.Chanda, D.Lodh, and S.L.Ray: Arsenic Exposure and Health Effects IV ,(2001), pp.27-52

13) M.E.Schreiber, J.A.Simo, and P.G.Freiberg: Hydrogeol.Journ., 8(2000), 161-176

14) S.C.Peters, J.D.Blum, B.Klaue, and M.R.Karagas: Environ.Sci.Technol., 33(1999), 1328-1333.

15) R.T.Nickson, J.M.McArthur, W.G.Burgess, K.M.Ahmed, P.Ravenscroft, and M.H.Rahman Nature, 395(1998), 338

16) R.T.Nickson, J.M.McArthur, P.Ravenscroft, W.G.Burgess, and K.M.Ahmed: Applied Geochemistry, 15(2000), 403-413.

17) S.K.Acharyya, S.Lahiri, B.C.Raymahashay, and A.Bhowmik: Environ.Geo., 39(2000), 1127-1137.

18) T.Igarashi, T.Oyama, and N.Saito: Jour.Japan Soc.Eng.Geol., 42(2001) 214-221.

19) T.Igarashi, T.Oyama, and R.Hataya: The 11th Japan National Symposium for Rock Mechanics (2002), D02.

20) T.Tanaka: Applied Organometalic Chemistry, 2(1998), 283-295. 